Revista de Economia Política, vol. 30, $n^{\circ} 1$ (117), pp. 27-44, janeiro-março/2010

\title{
Ciência econômica e modelos de explicação científica: retomando a questão
}

\author{
LEDA MARIA PAULANI*
}

Economic science and scientific explanation models. Economics was born under the sign of methodological vagueness. The first author who tried to solve the question (John Stuart Mill) asserted that it is a kind of knowledge that uses the abstract (direct deductive) method but also that it is an exception because for all other phenomena in the field of moral science the correct method is the inverse deductive or historical method. On the other side, functionalist explanations that are condemned by the scientific precepts of economics are present in the science since its beginning with Adam Smith. Economics went ahead without worriment about these methodological issues but this indefiniteness has never gone off stage. Since the start of XXI century new facts are emerging. Developments in Psychology are giving a new breath to Friedman's point of view and seem to fortify the mainstream (Rogebert e Nordberg, 2005), whereas unfolding in complexity science promises to throw it down and put in its place another kind of explanation borrowed from Biology (Beinhocker, 2006). All this stimulates to retake the question. We do this here, under a critical vision, taking the taxonomy of scientific explanations framed by modern positivism.

Keywords: economics; scientific explanations models; deductive model; induction, ideology.

JEL Classification: B14; B40; B41.

\footnotetext{
* Professora titular do Departamento de Economia e do Programa de Pós-graduação em Economia da FEA/USP. E-mail: paulani@uol.com.br. Versão modificada do texto preparado para a prova de erudição do concurso de professor titular da FEA-USP, ocorrido em 10 e 11 de maio de 2007. Agradeço a Ana Bianchi, Basília Aguirre, Christy Pato, Denise Cyrillo, Eleutério Prado, João Machado Borges Neto, João Sayad, Luis Carlos Bresser-Pereira, Mário Duayer, Pedro Fonseca, Rodrigo Teixeira e Tomás Rotta, e a um parecerista anônimo desta REP, que contribuíram com comentários e sugestões à versão original e/ou a esta versão em forma de artigo. Os equívocos são meus. Submetido: Novembro 2007; Aprovado: Dezembro 2009.
} 


\section{INTRODUÇÃO}

A Ciência Econômica nasce sob a marca da indefinição metodológica. Dentre os pensadores clássicos, foi John Stuart Mill quem primeiro tentou decidir a questão. No famoso ensaio de 1836, ele a proclama como ciência dedutiva. Poucos anos mais tarde, porém, proclama para todo o universo das ciências morais o método inverso. A marca da indefinição está também presente no fato de explicações que podem ser associadas ao modelo funcional ou genético jamais terem sido aceitas pelos cânones da ciência, a despeito de estarem presentes desde Adam Smith.

A ciência econômica seguiu seu caminho, sem se preocupar muito com esses assuntos metateóricos. Mas esse problema nunca saiu de cena. Hayek fustigou o paradigma dominante com uma discussão metateórica em 1937. Friedman, assentado em pressupostos pragmatistas, deu novo alento a esse mesmo paradigma em 1953. Em 1983, D. McCloskey embaralhou mais uma vez a discussão, asseverando que o verdadeiro método do paradigma dominante era pura e simplesmente a retórica. Desde o início do século XXI, fatos novos estão surgindo. Desenvolvimentos na área da Psicologia dão novo alento à visão friedmanita e parecem fortalecer o paradigma dominante (Rogebert e Nordberg, 2005), enquanto desenvolvimentos da chamada ciência da complexidade prometem jogá-lo pelos ares e colocar em seu lugar outro tipo de explicação, emprestada da biologia (Beinhocker, 2006).

Tudo isso incentiva uma retomada da questão. É o que se faz aqui, a partir de uma perspectiva crítica, de orientação materialista. Na primeira seção, tomando por base os modelos de explicação científica tal como colocados pelo positivismo moderno, discutimos a relação entre ciência econômica e modelo dedutivo; na segunda seção invertemos a operação e apresentamos a relação entre ciência econômica e indução; finalmente, na terceira seção, mudando de orientação epistemológica e deixando de lado o enquadramento positivista, resgatamos a relação entre ciência econômica e ideologia, buscando atualizá-la. Uma observação final fecha o trabalho.

\section{A CIÊNCIA ECONÔMICA E O MODELO DEDUTIVO: VÍCIO RICARDIANO E TEORIAS ABSURDAS}

O positivismo moderno classifica os argumentos que podem ser considerados científicos em quatro modelos distintos. O modelo dedutivo-nomológico, típico da lógica e da matemática, o modelo indutivo-probabilístico, típico da química, o modelo funcional ou teleológico, típico da biologia, e o modelo genético, típico da linguística e da história. ${ }^{1} \mathrm{O}$ modelo indutivo-probabilístico é visto também como um corpo de regras que deve ordenar toda a atividade experimental das chamadas ciências. Não por acaso, esse modelo praticamente se fundiu com o primeiro, ge-

\footnotetext{
${ }^{1}$ A classificação está em Nagel (1981), espécie de bíblia dessa orientação epistemológica.
} 
rando o modelo hipotético-dedutivo, que é hoje tomado como o paradigma maior das explicações científicas.

Diante desse quadro, onde inserir a ciência econômica? O primeiro pensador a enfrentar decididamente a questão foi John Stuart Mill. Mas ele não se saiu muito bem da empreitada. Mill se viu confrontado entre o método dedutivo abstrato, para ele típico da geometria, e o método que ele sintomaticamente vai chamar de "dedutivo inverso", o qual não é nada mais do que o método experimental e indutivo que o pensamento do século XIX, particularmente pelas mãos de Comte, ia advogando como o método que mais se adequava às ciências da sociedade que então nasciam.

No famoso ensaio de 1836, Mill defende sem titubear o caráter dedutivo e abstrato da economia política, e é aí que depara com o constructo mais importante dessa ciência, o homem econômico. Mas isso foi antes de o mesmo Mill escrever seu magistral A System of Logic, publicado em 1843. No livro VI dessa obra, ele trata especificamente das "Ciências Morais", hoje "Ciências Sociais" e, ao contrário do que fizera no ensaio de 1836, reivindica para elas, como o único adequado, o método "dedutivo inverso".

Isto posto, é evidente a contradição em que Mill se envolve, a menos que julguemos que os fenômenos econômicos não fazem parte dos fenômenos sociais. Poderia ter sucedido que Mill tivesse mudado de ideia, o que seria perfeitamente possível, pois nesse meio-tempo, ou seja, entre a publicação de um e outro trabalho, dizem seus biógrafos, Mill leu a obra de Comte, que o impressionou profundamente. ${ }^{2}$ Contudo, não é disso que se trata, pois, na "Lógica das Ciências Morais", Mill mantém praticamente intactas as colocações do ensaio de 1836 e continua a defender, para a ciência da economia política, como uma exceção que resta inexplicada, o raciocínio a priori e abstrato que caracteriza o modelo dedutivo.

Cabe colocar aqui, pela primeira vez, a pergunta cuja resposta procuramos: que saber é esse que nasce com a Modernidade e que se afirma pari passu à consolidação do próprio capitalismo? Ele tem necessariamente de ser construído a partir de proposições abstratas, ou ao contrário, suas leis não podem ser senão experimentais, produzidas pela observação de regularidades empíricas que experiências históricas diversas podem gerar?

Mas a confrontação em que se enrodilhou Mill foi tão somente um capítulo metateórico de uma história teórica que começara antes. Discorrer sobre os fatos econômicos por meio de uma sequência de proposições logicamente conectadas fora a forma permanente de raciocinar de David Ricardo. O caráter dedutivo de suas explicações era tão acentuado que incomodou Henry Brougham, seu companheiro no parlamento inglês, que assim se pronunciou sobre o colega: "As concepções do Sr. David Ricardo são na verdade abundantemente teóricas [...] de vez em quando extravagantes, graças à propensão que o Sr. Ricardo tem de levar um princípio até às últimas consequências, como se fosse um ser do outro mundo, ou como

\footnotetext{
${ }^{2}$ A esse respeito, ver Mattos (1998), principalmente, introdução e capítulo 1.
} 
se fosse um engenheiro que construísse uma máquina sem levar em conta a resistência do ar em que ela vai operar e a força, o peso e a fricção das partes que a compõem" (David, 1998, p. 423).

O incômodo do companheiro de Ricardo era com o caráter absolutamente abstrato de suas formulações, já que elas se destinavam a referendar proposições concretas de política econômica. É por conta disso que Schumpeter vai denominar "vício ricardiano" à vinculação de formulações abstratas a questões práticas. Mas esse não foi um vício que pudesse ser creditado à imaturidade da jovem ciência. Um teórico insuspeito como Frank Hahn, que junto com Kenneth Arrow e Gérard Debreu compôs o mais importante conjunto de economistas do programa de pesquisas do equilíbrio geral, reclamava, num texto de 1984, da indevida utilização que os monetaristas em geral faziam desse paradigma, como se ele estivesse descrevendo as economias reais. "Tendo gasto a maior parte de minha vida como um economista dessa teoria”, diz Hahn, "confesso que uma tal interpretação jamais me ocorreu. $\mathrm{Na}$ verdade, era claro, desde o início, que nós só tínhamos meia teoria, uma vez que não havia (e não há) nenhuma explicação rigorosa sobre como o equilíbrio de Arrow-Debreu vem a ser estabelecido. Mas percebeu-se rapidamente que mesmo essa metade que nós tínhamos possuía sérias falhas: ela não podia explicar o dinheiro ou as mudanças de estoque [...] Se se toma a teoria walrasiana seriamente, não se pode levar a sério o uso que os monetaristas fazem dela” (p. 309).

Frank Hahn fala com a autoridade de quem participou ativamente da confecção do artefato teórico mais logicamente consistente com a ideia da ciência econômica como explicação dedutiva já produzido. Sua franqueza quanto à total insuficiência desse paradigma para explicar o mundo em que realmente vivemos nos leva imediatamente a perguntar: se não se trata disso, do que se trata então? Sobre essa questão não será demais lembrar um episódio ocorrido justamente com Gérard Debreu, quando da cerimônia de recebimento de seu Nobel de Economia, em 1983. Segundo consta, ao final do evento, em meio a dezenas de jornalistas que o cercavam, foi-lhe perguntado o que achava ele, àquela altura o mais importante economista do planeta, da política de juros do presidente Reagan que, por sua radicalidade, tinha se tornado o assunto predileto das rodinhas especializadas. Para assombro dos presentes, Debreu respondeu singelamente que não fazia a menor ideia do tema sobre o qual era indagado, pois não se preocupava com esses assuntos de política econômica e só fazia modelos abstratos.

Para os menos avisados, a inesperada resposta talvez tenha parecido tão somente a sonsice de um francês arrogante, que queria sutilmente revelar seu desprezo pelos assuntos americanos. Mas evidentemente não era disso que se tratava e sim de mais um rompante de sinceridade de um teórico do equilíbrio geral. Se Debreu não tinha de fato o que dizer, se todo seu conhecimento de teoria econômica, que lhe tinha rendido um prêmio Nobel, não permitia que ele pronunciasse uma palavra sequer sobre tema tão escandalosamente econômico, cabe-nos repetir a pergunta que já havíamos feito: de que trata então essa teoria? De que mundo ela fala?

A posição pouco confortável dos teóricos do equilíbrio geral é substituída, por quem tem a opinião oposta, por uma posição não menos desconfortável. Milton 
Friedman, seguramente o mais célebre dos monetaristas que estão na mira das críticas de Frank Hahn, notabilizou-se justamente pela defesa do irrealismo dos supostos teóricos, apresentada em famoso ensaio escrito em 1953.

É bem verdade que Friedman refere-se aí não à versão walrasiana do paradigma do equilíbrio, mas à versão marshalliana dele, mas sua crítica ao modelo walrasiano radicava em sua incapacidade de fornecer hipóteses testáveis, não à irrealidade do mundo por ele construído. O ensaio de Friedman teve uma repercussão extraordinária e marcou gerações inteiras de economistas filiados ao mainstream, um nome sob o qual passa a se abrigar toda a teoria econômica convencional. $\mathrm{O}$ pragmatismo militante ali tão calorosamente defendido por Friedman fornecia aos adeptos dessa corrente os melhores argumentos para a defesa da crítica de que a teoria de extração neoclássica partia de pressupostos irrealistas, devendo, por isso, ser abandonada.

Contudo, é evidente que a posição é pouco confortável e esse desconforto está até hoje presente. "Os economistas são loucos?”, perguntam-se Ole Rogeberg e Morten Nordberg, em artigo de 2005. Resgatam aí a questão que, segundo Roger Backhouse, é a questão metodológica chave da ciência econômica contemporânea: "De que forma um modelo que se baseia em suposições tão flagrantemente não verdadeiras pode nos dizer alguma coisa sobre o mundo real?" (Backhouse apud Rogeberg e Nordberg, 2005, p. 543). Mas os referidos economistas não escrevem o dito artigo para criticar o mainstream e sim para resgatá-lo desse desconforto. "Uma defesa das teorias absurdas na ciência econômica" é o nome do trabalho.

De modo muito inteligente, eles tentam defender o irrealismo das suposições apelando para a limitação da capacidade cognitiva humana. Seu ponto central, que vão buscar na psicologia, é que a mente humana é incapaz de raciocinar sem modelos mentais, de modo que a construção de teorias "como-se" impõe-se como uma necessidade aos economistas. Revigoram com isso a defesa algo rude feita por Friedman do necessário irrealismo dos supostos teóricos, pois não se trata, para eles, de desprezar o conteúdo de realidade dessas proposições, mas de respeitar um constrangimento que advém da forma mesma de se pensar racionalmente. Alertam, contudo, e por isso o resgate do desconforto que eles promovem é apenas parcial, que isso não implica a defesa incondicional de toda e qualquer construção teórica, e admitem que, em muitos casos, os modelos baseados no axioma da escolha racional passaram do ponto, tornando-se praticamente impossível compreendê-los intuitivamente.

Eles não fornecem nenhum exemplo concreto de algum modelo que tivesse sofrido desse mal, mas não custa lembrar a esse respeito a manifestação de outro economista, este brasileiro e insuspeito de qualquer simpatia pelas visões críticas do mainstream, sobre a teoria das expectativas racionais. Diz Mário Henrique Simonsen: "Na década de 1980, quando o marxismo caiu na contramão da história, tive que debater a teoria das expectativas racionais [...] O fundamento da teoria é 
um estelionato verbal: considera-se racional quem se comporta de acordo com a teoria". ${ }^{3}$

Mas, voltando à sofisticada defesa do irrealismo dos supostos que fazem Rogeberg e Nordberg, diríamos que tudo estaria então menos mal para o mainstream não fosse por um pequeno detalhe: uma das principais regras do positivismo moderno aponta a verdade dos enunciados que funcionam como premissas explicativas como a primeira condição epistêmica que qualquer explicação dedutiva deve cumprir. Isto posto, é forçoso concluir que a corrente principal da teoria econômica encontra-se desde há muito em maus lençóis no que tange à metodologia que supostamente abraça e cabe-nos mais uma vez perguntar: que tipo de saber é esse que a ciência econômica tomada como eminentemente dedutiva produz?

\section{A CIÊNCIA ECONÔMICA E A INDUÇÃO: FALSEACIONISMO DE FACHADA E BAGUNÇA METODOLÓGICA}

A referência à questão do conteúdo epistêmico dos enunciados teóricos nos permite agora investigar o outro grande modelo de explicação científica, o modelo indutivo-probabilístico. Considerado como um tipo menor de explicação, o modelo indutivo afirma uma proposição genérica a partir da verificação de um determinado número de implicações a ela atribuível. Vítima daquilo que os positivistas denominam de "falácia da afirmação do consequente", a validade desse tipo de explicação é resgatada pelo estratagema popperiano. Como se sabe, Popper vai inverter a questão da validação de tais proposições asseverando que, se não se pode racionalmente afirmar enunciados genéricos ou leis universais, pode-se, no entanto, racionalmente refutá-los. Com isso, o poder da razão humana, castigado pelo ceticismo humeano, retorna pela porta dos fundos, mas obriga todos os cientistas a estoicamente submeterem ao falseamento suas mais belas e trabalhadas hipóteses e teorias. Para Popper, o objetivo da ciência não é o impossível descobrimento das verdades últimas, mas a elaboração de conjecturas, que devem ser submetidas ao tribunal da experiência.

Também para Adam Smith a verdade, ela mesma, está além do alcance de qualquer teoria. Em seu texto The principles which lead and direct philosophical inquiries, ele compara o estudioso que quer encontrar explicações sobre o mundo aos espectadores de ópera dos grandes teatros de Londres e Paris. A diferença, diz ele, é que, "encerrada a apresentação, os espectadores podem ir atrás das cortinas

\footnotetext{
${ }^{3}$ Procurei, de todas as formas possíveis, detectar a origem desse pronunciamento de Simonsen, mas não fui bem-sucedida. Soube de sua existência por intermédio da revista Controversa, publicada pelo CAVC da FEA/USP, mas ela não trazia sua origem. Encontrei-o novamente como epígrafe de um artigo de Marcelo Curado publicado no n. 1 de 2006 da revista Economia e Sociedade, editada pelo Instituto de Economia da Unicamp, mas tampouco ali havia a informação sobre sua origem.
} 
e descobrir os mistérios dos maquinários que tornaram possível aquele grande espetáculo, enquanto aos espectadores da vida não é dada a chance de espiar atrás das cortinas do grande e maravilhoso espetáculo da natureza." (Smith apud Evensky, 1998, p. 469). Para ele, as teorias são sempre provisórias e falhas, não porque as evidências podem vir a contrariá-las, mas porque elas são uma construção da imaginação (Evensky, 1998, pp. 469-470).

Observando o mundo, no caso o mundo britânico do final do século XVIII, que experimentava os efeitos superlativos da revolução industrial e da profunda difusão dos mecanismos de mercado, Smith imaginou que há uma ordem na natureza e que essa ordem é produto do desígnio de um Deus bondoso. Sendo assim, a história deve seguir um curso vuirtuoso, cheio de bons presságios. Essa imaginação ele a objetivou em sua obra mais famosa e não procurou, a cada momento, encontrar evidências que falseassem sua imaginação, se não o contrário. A Riqueza das Nações é repleta de descrições e citações que buscam comprovar empiricamente suas afirmações.

Sobre esta última observação, poder-se-á com razão argumentar que, sendo o falseacionismo uma filosofia da ciência que é mais normativa do que descritiva, muito estranho seria que Smith tivesse se comportado como um popperiano avant-la-lettre. Mas a não observância dos critérios metodológicos pelos economistas é mais regra do que exceção.

Por exemplo, os trabalhos empíricos sobre as regras de formação de preço pelas empresas não tiveram praticamente nenhum impacto sobre o andamento normal da ciência, de modo que, nos livros texto, predomina a ideia de que os ofertantes são price-takers, sendo que ninguém nunca se lembra de perguntar quem define então esse preço que é tomado como dado. Exemplo, talvez ainda mais importante, vem de Ronald Coase, que ganhou o prêmio Nobel em 1991 por um trabalho teórico sobre a natureza da firma assentado sobre intensas pesquisas empíricas e feito 54 anos antes. Coase afirmou, na abertura de um congresso nos Estados Unidos em 1997, que infelizmente ele não podia dizer que sua ciência tinha progredido ao longo desse tempo todo. Pelo contrário, continuava uma economia de quadro-negro, que vive nas mentes dos economistas, mas não na face da Terra. ${ }^{4}$ De fato, nos manuais de economia, o modelo de equilíbrio em concorrência perfeita continua lá, e trabalhos como o de Coase não aparecem sequer nas notas de rodapé.

No mesmo sentido, os fortes questionamentos efetuados, pelo menos desde os anos 1970, à forma neoclássica de tratar as preferências, praticamente não afetou o modo de raciocinar dessa corrente. Pouco adiantou demonstrar a impossibilidade prática de tratá-las como sendo inteiramente exógenas; quase nenhum impacto teve a admoestação feita por Georgescu-Rogen de que elas não são estáveis e de que mudam com o tempo; de nada adiantou mostrar que elas são intransitivas e, por-

\footnotetext{
${ }^{4} \mathrm{O}$ congresso ao qual me refiro aconteceu na Washington University, em St. Louis (EUA). A referência à fala de Coase aqui apresentada foi reconstituída de memória, pois eu me encontrava lá.
} 
tanto, inconsistentes. ${ }^{5}$ Por fim, a pecha de "rational fools", aplicada por Amartya Sen à noção de racionalidade como mera consistência de escolhas, não colou. ${ }^{6}$

Finalmente, parece claro que a perspectiva geral da economia neoclássica não dá conta de uma enorme gama de fenômenos empíricos. A presença de flutuações cíclicas de períodos de tempo e amplitudes irregulares não parece consistente com a ideia de que a economia retorna ao equilíbrio, depois de qualquer distúrbio. A persistência do desemprego mina o suposto de que salários e preços movem-se no sentido de reduzir os desequilíbrios. A manutenção de fortes desigualdades entre as rendas nacionais per capita, a despeito da difusão da tecnologia ao longo do planeta, contraria aquilo que a teoria prevê. E quem faz essas últimas observações é Kenneth Arrow, outro prêmio Nobel, companheiro de Gérard Debreu e Frank Hahn no programa de pesquisas do equilíbrio geral (Arrow apud Jarsulic, 1998, pp. 60-61).

Alguém poderia com razão argumentar que essas últimas observações de Arrow têm outra natureza, visto que estão relacionadas à economia como um todo e têm caráter mais "macro", não podendo se exigir de um paradigma associado quase exclusivamente à micro que ele dê conta dessas explicações. Contudo, a corrente principal advoga hoje em dia justamente isso: que quaisquer considerações de natureza macroeconômica devem estar assentadas em sólidos fundamentos micro. Foi essa a natureza da revanche que o paradigma neoclássico promoveu em meados dos anos 1970 contra o approach keynesiano, pois a economia novo-clássica não é senão o velho monetarismo de Friedman, modernizado pelas expectativas racionais.

A afirmação de que a macroeconomia só pode ser considerada científica se for assentada em fundamentos micro e, mais ainda, como quer Lucas, que, se corretamente operada, a ciência econômica verá o fim da distinção micro \& macro, ${ }^{7}$ é indicação clara de que, na visão da corrente principal, a ciência econômica toma-se a si mesma como completamente dedutiva, da base ao topo. Ela reivindica validade geral assentada no modelo hipotético-dedutivo e abraça uma posição metodológica que combina o irrealismo dos supostos teóricos com o falseacionismo popperiano. Não pode, portanto, eximir-se de explicar os fenômenos empíricos de que nos fala Arrow. Contudo, nem sequer o trabalho puramente lógico-formal de vincular os fenômenos agregados a seus supostos microfundamentos foi ainda completado. Só para citar um exemplo, o teorema da impossibilidade de Arrow e os resultados do modelo de Sonnenschein, Mantel e Debreu - o qual mostra o caráter arbitrário da curva de demanda agregada - apontam para a completa impropriedade de se explicar os eventos em nível macro tomando-se por base a agregação

\footnotetext{
${ }^{5}$ A lista de restrições à teoria neoclássica da escolha, ainda que sem o conteúdo interpretativo aqui apresentado pode ser encontrada em Nicolaides (1990).

${ }^{6}$ Agradeço a Ana Bianchi a lembrança muito pertinente dessa observação de Amartya Sen.

7 “Se esses desenvolvimentos [dos problemas de agregação, como inflação e ciclos - LMP] forem bem-sucedidos, o termo 'macroeconômico' simplesmente cairá em desuso e o complemento que o modifica, 'microfundamentos', será supérfluo. Nós estaremos falando então, como o fizeram Smith, Ricardo, Marshall e Walras, simplesmente de teoria econômica” (Lucas apud Janssen, 1998a).
} 
dos comportamentos individuais. ${ }^{8}$ De modo ainda mais grave, os teóricos da complexidade questionam a viabilidade lógica da construção do próprio mapa individual de preferências, problematizando sobremaneira a possibilidade de se pensar a formação de preços com base nas curvas de demanda e oferta.

Ora, e com tantas e tamanhas violações daquilo que os próprios economistas aceitam como sendo hoje o "método científico" encontra-se, por exemplo, nas primeiras páginas do celebrado manual de introdução de Mankiw a seguinte afirmação: "Os economistas tentam tratar seu campo de estudo com a objetividade de um cientista. Eles formulam teorias, coletam dados e depois analisam esses dados para confirmar ou refutar suas teorias". Cinismo?

Perante tudo isso, a transgressão metodológica de Smith parece, em sua ingenuidade, plenamente desculpável. Voltemos então ao pai da ciência econômica e retomemos os dois modelos de Mill. Se observarmos bem o procedimento de Smith, veremos que ele está muito distante do método de investigação que Mill considerou como sendo próprio da ciência econômica, ou seja, o método dedutivo. Ao contrário, ele parece estar muito próximo do método que Mill chama de dedutivo-inverso, o qual, como vimos, é o método experimental e indutivo, que hoje carrega o apêndice do falseacionismo. A classificação só não é inteiramente correta, porque a forma de proceder de Smith prenuncia muito mais do que o predomínio dos raciocínios histórico-indutivos que caracterizariam o pensamento sobre os fenômenos sociais.

Para perceber isso é preciso lembrar que a metáfora mais famosa da ciência econômica, que saiu da pena de Smith, deve ser vista como atuando de duas formas distintas. A primeira delas é aquela que faz com que os preços de mercado gravitem em torno dos preços naturais. $\mathrm{O}$ "equilíbrio" que aparece posto por esse movimento tem um caráter contraditório, pois tem como pressuposto um mundo em ebulição, em que cada um dos agentes, seguindo suas particulares estratégias, busca seu equilíbrio individual, o qual, no entanto, raras vezes é obtido.

Para falar na linguagem dos teóricos da complexidade, ao contrário do que parece, o sistema como um todo está permanentemente longe do equilíbrio. A racionalidade indutiva dos agentes faz com que eles, buscando atingir seus objetivos, mudem incansavelmente seus padrões de comportamento e, a despeito do fato de que nenhum deles consegue realizar $100 \%$ do que planejou, ou justamente por isso, o padrão de preços que daí resulta acaba por exibir uma certa regularidade. Nesse sentido, Prado (2006) apresenta uma formalização da mão invisível entendida então não como a coordenação ótima dos planos de agentes dotados de racionalidade perfeita, mas como o processo de auto-organização inerente à dinâmica competitiva dos capitais, a qual está por trás da aparência de equilíbrio do sistema.

O que a economia neoclássica fez foi tomar esse aparente equilíbrio como sendo positivamente posto e buscar esclarecê-lo. Daí a necessidade de desenhar agentes burocráticos, dotados de uma enorme capacidade de processamento de

\footnotetext{
${ }^{8}$ Apoio-me aqui em Janssen (1998a) e Rizvi (1998).
} 
informações, cujo comportamento converge sempre para o modelo "correto" ou de "previsão perfeita", ou seja, agentes em tudo opostos àqueles imaginados pelo pensador escocês.

Em outras palavras, pelo menos no caso de Smith, os homens de carne e osso que atuam nos mercados não podem ser vistos como átomos de comportamento idêntico e altamente previsível. A mão invisível que funciona aí, atua como uma espécie de maestro de orquestra, mas uma orquestra onde os músicos são idiossincráticos, rebeldes e mal-educados. Esta, aliás, é a razão pela qual Hayek, pressionado no famoso debate sobre o cálculo socialista justamente pela demonstração de que o indivíduo subjacente à teoria neoclássica permitia o planejamento e o desenho a priori do ótimo social, vai desancar com essa metodologia em seu famoso ensaio de 1937, afirmando com todas as letras que o verdadeiro individualismo era aquele presente em Smith.

A natureza desse tipo de explicação já aponta na direção do modelo funcional-teleológico, pois o que Smith está de fato afirmando é que a sociedade organizada materialmente pelo mercado produz uma sorte de ordem espontânea que não está previamente nas intenções de ninguém, concepção de resto idêntica à do próprio Hayek, que a chamou de cataláxia. Mas é a segunda das formas de atuar da mão invisível que vai mostrar a existência desse tipo de explicação no raciocínio de Smith de um modo ainda mais evidente. O curso auspicioso para o homem que ele preconizou decorria da seguinte ordem de considerações: o caráter autocentrado do homem faz com que ele tenha uma propensão natural à troca, a qual leva à divisão do trabalho e ao crescimento da produtividade; esse crescimento da produtividade leva necessariamente ao crescimento da produção e à riqueza da Nação, um resultado, este último, que não fazia parte das intenções de ninguém.

Ora, qual é natureza desse tipo de argumento? Trata-se cristalinamente de um argumento de natureza funcional, forma de raciocinar típica do modelo funcional-teleológico, que tem na biologia sua área paradigmática e que é considerado, pelos cânones científicos vigentes, como sendo absolutamente proibido no domínio das ciências sociais. Nesse tipo de argumento, explica-se o que vem antes pelo que vem depois, não o que vem depois pelo que vem antes e explica-se o comportamento das partes pelo todo, não o todo pelo comportamento das partes.

Essas classes de explicações só são admitidas pelo moderno positivismo no domínio do mundo natural, visto que aí se admite, como causação científica, o papel funcional que uma determinada unidade tem, dentro de um organismo, para manter a própria vida. No mundo dos fenômenos sociais, porém, a explicação teleológica é considerada anticientífica, porque implica aceitar que o futuro é o agente de sua própria realização, ou que há entidades que transcendem os indivíduos e que se movem autonomamente.

É bem verdade que, com um pouco de boa vontade, descobrimos na Riqueza das Nações o feedbacklooping que torna tolerável esse tipo de explicação mesmo nas 
ciências sociais. ${ }^{9} \mathrm{O}$ crescimento da riqueza aumenta o tamanho do mercado, única condição necessária para que vá em frente o processo de divisão do trabalho que desencadeia o ciclo virtuoso, e a reiteração desse resultado reforça o comportamento dos agentes nessa direção. ${ }^{10}$ Contudo, é também verdade que isto não está ali colocado com todas as letras, o que torna legítimo afirmar que, pelo menos no caso da promoção da riqueza de todos, a mão invisível de Smith constitui uma explicação funcional típica, dessas absolutamente abominadas pelo cânones científicos.

Seja como for, o que nos interessa destacar é que a forma de proceder de Smith contém muito mais do que o método dedutivo inverso de Mill. Ela junta na mesma explicação o argumento indutivo com o argumento funcional e abre espaço também para o argumento genético, visto que a indução de que aqui se fala tem natureza histórica. As comprovações empíricas das teses que Smith nos apresenta têm recorrentemente a forma de exposições históricas, nas quais, como sói ocorrer com esse tipo de explicação, o passado é recortado de forma a referendar a suposição da qual se partiu. Essa, aliás, a razão pela qual esse tipo de argumento é visto como sendo de categoria inferior pelo positivismo moderno.

Mas se uma conjunção de argumentos de natureza metodológica tão distinta está no nascedouro mesmo de nossa ciência, alguns dos quais considerados como inferiores ou mesmo inaceitáveis cientificamente, não custa mais uma vez perguntar: que tipo de saber é esse afinal? É um saber de segunda classe, porque é indutivo, funcional e histórico, ou não é nada disso e deve ser incluído, enquanto saber de primeiro nível, dentro da classe de conhecimentos de natureza inequivocamente dedutiva como queria Mill? Mas se abandonamos Smith em sua simpática bagunça metodológica e voltamos a aproximar nossa ciência do modelo dedutivo, não nos deparamos com a circunstância de que, para ser assim considerado, ele é obrigado, a menos do vício ricardiano, a admitir que é incapaz de falar sobre o mundo no qual realmente vivemos? Em que pé ficamos então?

Bresser-Pereira $(2003,2006)$ apresenta uma solução para esse dilema, mas ela tem, parece-me, um caráter essencialmente pragmático: trata-se de conviver com os dois tipos de argumento, utilizando-se ora um, ora outro, conforme a conveniência e o tipo de problema que se busca tratar, mesmo que isto implique a aceitação resignada de uma "consistência menos abrangente". ${ }^{11}$

Aventuro-me aqui a encaminhar o problema de uma outra forma. Uma parte das respostas àquelas perguntas implica questionar a própria epistemologia positivista, que não só coloca em caixas separadas procedimentos e tipos de explicação que muitas vezes caminham conjuntamente, como dita regras draconianas sobre o que pode ou não ser considerado científico de um modo que se choca com a

\footnotetext{
${ }^{9}$ A esse respeito vide, por exemplo, Elster (1989).

${ }^{10}$ Sobre essa interpretação da visão smthiana ver também Foley (2003, cap.1).

${ }^{11}$ Bresser Pereira faz em realidade mais do que isso e tenta encontrar as justificativas para se proceder dessa forma. Trata-se de uma discussão bastante interessante, que merece um tratamento cuidadoso, o qual, no entanto, foge ao escopo do presente artigo.
} 
própria história da ciência. E não são apenas os adversários declarados dessa visão, como Thomas Kuhn e Paul Feyerabend que postulam a impropriedade de tal epistemologia. A falência do projeto desenhado pelo Círculo de Viena e a impossibilidade então percebida de se construir uma linguagem $100 \%$ científica, joga na mesma direção.

Mas esse tipo de resposta não é nem de longe suficiente. Se nos contentarmos com ela cairemos inevitavelmente em algum desvão do pós-modernismo, hoje tão em voga, e estaremos então agindo como os hegelianos de esquerda, que foram companheiros de Marx em sua juventude: como cordeiros que pensam que são lobos e que vociferam contra as ideias, enquanto o mundo segue inabalável o seu curso. Cabe, portanto, trazer para o centro do debate as raízes materiais da produção do discurso econômico. Elas nos mostrarão os vínculos entre esse tipo de conhecimento e o solo social que o produziu. Essa mudança de paradigma em direção ao materialismo permite-nos ir além da dicotomia "dedução x indução" e trazer outros elementos para a análise da questão.

\section{PARA ALÉM DA DICOTOMIA DEDUÇÃO X INDUÇÃO: CIÊNCIA ECONÔMICA E IDEOLOGIA}

Quando inverteu a proposta hegeliana e deu-lhe um conteúdo material, o que Marx fez, além de fundar o materialismo histórico, foi transformar em crítica da Ideologia à Dialética que Hegel tinha recriado. É fato sabido que a intenção de Hegel tinha sido a de recuperar o Espírito do afundamento no sensível, no vulgar e no singular que parecia ser a característica dos novos tempos. Para ele, enfrentar a fragmentação do homem novo que nascia implicava criticar o discurso do entendimento e as oposições filosóficas características dos sistemas modernos: natureza e espírito, eu e não eu, finito e infinito. A inversão operada por Marx vai mostrar que o que estava por trás dessa recriação da Dialética era a pobreza da realidade alemã dos inícios do século XIX. Fora o contato com uma realidade a eles não congruente dos saberes sobre si mesmas e seu mundo que as classes vitoriosas construíam nos países avançados que resultara na exumação alemã da Dialética. ${ }^{12}$

Mas Marx percebe que não se tratava por isso de jogar fora o sistema construído por Hegel. Essa operação, produzida pela especificidade da realidade alemã, tinha desembocado num resultado duplo: de um lado a apresentação da contradição como a efetivação da própria Razão; de outro, considerando-se principalmente a versão gerada pelos epígonos de esquerda do grande pensador, a possibilidade de se perceber o caráter ideológico das doutrinas sobre a Modernidade de modo mais fácil do que no local mesmo de sua produção. Tratava-se, portanto, para Marx, na expressão que ficou famosa, de "descobrir o cerne racional da Dialética

\footnotetext{
${ }^{12}$ Apoio-me aqui inteiramente em Arantes (1996, 1996a).
} 
dentro de seu invólucro místico" e o cerne racional, para ele, estava no terreno vivo de onde brotara a Economia Política.

Para o Marx que já fizera a crítica do hegelianismo de esquerda, o saber nunca pode ser visto como produto de si mesmo ou do desenvolvimento geral do espírito humano. Ele tem que ser visto, antes de mais nada, como produto social, como produto histórico, de modo que a ideologia pode tanto ser uma visão distorcida dessa história quanto uma abstração completa dela. Partindo dessa perspectiva, Marx vai encontrar na realidade contraditória do mundo capitalista o fundamento das contradições carregadas pela Economia Política de Smith, Ricardo e Mill.

Uma sociedade de classes que aparece como sociedade sem classes, um indivíduo que aparece como soberano, mas que é completamente dependente e que só por isso pode ser indivíduo, uma produção que visa apenas o incessante movimento do ganho e que aparece como produção para satisfazer necessidades humanas, uma apropriação de trabalho não pago que aparece como apropriação pelo trabalho próprio, uma tal realidade, enfim, só poderia produzir um saber eivado ele mesmo de contradições. Um saber afinal, ideológico, que não era falso em si, pois revelava pelo avesso a realidade movida pela contradição que os novos tempos produziam, mas que tampouco podia ser considerado inteiramente científico.

Tratava-se, portanto, de uma sorte de falsa consciência, a qual era produzida pela natureza contraditória do próprio capitalismo. O modo de produção capitalista aparecia como simples sociedade mercantil, tocada a liberdade, mérito e equivalência e essa aparência era fundamental para que o sistema pudesse ser o que era. Os economistas clássicos investigaram esse nível fenomênico, e esse nível não era propriamente uma falsidade, pois era parte inseparável da forma de existir dessa realidade. Mas era preciso por isso fazer a crítica da Economia Política e revelar sua natureza ideológica. O titubeio de Mill pode ser considerado então apenas a reflexão, no nível metateórico, das limitações e contradições carregadas por esse saber em seu nascimento, as quais resultavam por sua vez do caráter contraditório da própria realidade a partir da qual ele pôde ser produzido. Isto posto, cabe perguntar se a análise de Marx resistiu ao tempo.

No prefácio da segunda edição de O Capital, que escreve em 1873, Marx decreta a sentença de morte da economia científica burguesa. Para ele, depois que a burguesia tinha conquistado o poder político na Inglaterra e na França, a luta de classes tinha assumido na teoria e na prática formas cada vez mais explícitas, como o demonstrara o vulcão social de 1848. Desmantelava-se assim, também no plano fenomênico, a ideia de uma sociedade de iguais, de um mundo sem privilégios, onde todos se beneficiavam das virtudes, que a providência do mercado garantia. O caráter de classe da nova sociedade que nascera no Ocidente tinha sido escancarado pela História e não podia mais ser ignorado. Os verdadeiros economistas políticos, observa Marx, tentavam ainda, num esforço desesperado, sintonizar a Economia Política do capital com as reivindicações não mais ignoráveis das massas trabalhadoras, tendo produzido um sincretismo desprovido de espírito, cujo melhor representante seria, para ele, justamente John Stuart Mill.

Mas o sino fúnebre daquela ciência já tinha soado, pois não se tratava mais 
de saber se este ou aquele teorema era ou não verdadeiro, mas se, para o capital, ele era útil ou prejudicial, cômodo ou incômodo. Na sua forma ferina de falar, Marx diz que, no lugar da pesquisa desinteressada entrou a soldadesca mercenária, no lugar da pesquisa científica imparcial entrou a má consciência e a má intenção da apologética. Marx não viveu o suficiente para testemunhar a profundidade da primeira grande crise do capitalismo, que jogou por terra de vez o sonho bom de Adam Smith, nem a força da revolução marginalista, que sintomaticamente nasceu no mesmo período e mudou o nome da ciência.

Ao arrepio da História e dos eventos que ela ia produzindo, a rebatizada ciência parte para um caminho que faz tábula rasa de tudo que efetivamente acontece. Foi o tamanho desse desacerto que produziu a revolução keynesiana, que tantas consequências teve, no plano teórico e no plano prático. Da ideologia enquanto visão invertida da história, a ciência da economia passara para o estágio da ideologia como abstração completa dela. Hayek também se incomodou com isso, já que, na visão dele, o mainstream fazia um trabalho contraproducente, colocando em xeque, ao invés de afirmar, as virtudes morais da economia de mercado e dando ensejo assim à vitória de visões intervencionistas como a de Keynes. Rompeu, por isso, radicalmente, com esse paradigma.

Cada um desses momentos constitui um capítulo da conturbada história da ciência econômica e de sua relação com o mundo real. O último capítulo, como sabemos, é a revanche da visão neoclássica por sobre as cinzas do mundo keynesiano. Qual o estado das artes hoje? Que sorte de ideologia, se é que ainda se pode usar o termo, a ciência econômica atualmente corporifica? Minha hipótese é que a combinação da abstração completa da história com a permanência do vício ricardiano e a falência do mundo de Keynes produziu um resultado inesperado até mesmo para a concepção marxista. Me parece que, na contramão dos supostos materialistas, o sistema capitalista se encontra hoje no melhor dos mundos, pois a produção de saber econômico que ele gera caminha agora também na mão contrária, vale dizer, das ideias para sua objetivação. Dou dois exemplos.

Chernavsky (2007) vasculha toda a literatura ortodoxa recente à caça de estudos que demonstrem de modo rigoroso, teórica e/ou empiricamente, a razão supostamente científica que justificasse a magnitude da taxa real de juros no Brasil dos últimos 12 ou 13 anos. E absolutamente nada encontra. A única alternativa que parece trazer algum alento atende pelo sugestivo nome de "função de reação do Banco Central". Mas dessa função podemos extrair o seguinte tipo de explicação: a taxa real de juros é o principal determinante da credibilidade da política monetária; a credibilidade da política monetária determina, por sua vez, a influência que as metas de inflação exercem sobre as expectativas inflacionárias, as quais constituem, segundo a função de reação, o determinante principal da própria taxa de juros. Ora, é evidente o caráter autorreferencial de tal "justificação", mas esse não é o principal problema. O principal problema é que, sendo assim, justifica-se qualquer taxa real de juros que promova a conversão das expectativas em relação à meta estabelecida. Isto significa que a magnitude em si que essas taxas efetivamente assumem é produto de um fenômeno puramente convencional. Em outras 
palavras, aquilo que se pensa e se convenciona torna-se realidade. Mas aquilo que se pensa não cai do céu, pois o dito mercado financeiro está no board do Banco Central e convenciona aquilo que lhe convém. A soldadesca mercenária não esgrima com ideias. Ela transforma suas ideias em realidade.

Vamos ao segundo exemplo. Em trabalho publicado ao final dos anos 1990, Bianchi (1998) relata os resultados da replicação que fez no Brasil do experimento sobre barganha realizado nos Estados Unidos por Carter e Irons. Por meio de um jogo de ultimato, buscava-se avaliar qual o peso da motivação autocentrada no comportamento de diferentes grupos. Ela trabalhou com dois grupos de estudantes universitários, o primeiro do curso de economia e o segundo do curso de ciências sociais e com dois estratos dentro desses dois grupos: estudantes iniciantes e estudantes já no final do curso. Os resultados mostram, para os dois grupos, um claro afastamento do modelo de racionalidade egoísta típico da ciência convencional, com valores como justiça e equidade aparecendo com peso significativo no comportamento dos estudantes. Mas o resultado mais interessante do experimento é que, quando se toma exclusivamente o grupo dos estudantes de economia em final de curso, seu comportamento se aproxima muito do comportamento esperado para o homem econômico racional típico, o que não acontece com os estudantes de economia em início de curso. Os irreais homens econômicos da teoria convencional são, hoje, portanto, produzidos, em alguma medida, pela própria teoria. A soldadesca interesseira produz a realidade que lhe convém e produz os homens que continuarão a produzi-la.

Levando em conta resultados como esses, qual o estatuto que tem hoje a ciência econômica convencional? Que já não se possa mais falar simplesmente em falsa consciência à moda da economia política clássica parece ter ficado claro. Talvez possamos enquadrá-la, então, numa espécie de falsa consciência esclarecida, uma posição ideológica que perde sua eficácia para modificar predisposições de conduta. ${ }^{13}$ Por exemplo, o caráter contraintuitivo da racionalidade do agente pressuposta na teoria das expectativas racionais é tão forte que ninguém em sã consciência se atreveria a afirmar que ela faz parte da realidade. Thomas Sargent, por exemplo, disse, numa conversa com Arjo Klamer, que está ciente de todos os problemas existentes com os supostos das expectativas racionais, que sabe das contradições filosóficas sobre seu uso, e que, no fundo, não acredita inteiramente neles, mas que continua a utilizá-los. Todos sabem, portanto, que pensar os agentes econômicos dessa forma é algo absurdo, mas continuam produzindo modelos explicativos e livros-texto de economia como se não soubessem. Mais que isso, foi esse o suposto teórico que, a partir dos anos 1970, virou de cabeça para baixo a macroeconomia e colocou os fundamentos micro dos fenômenos macro como condição sine qua non para a construção de explicações “científicas” para os fenômenos agregados.

\footnotetext{
${ }^{13}$ Nas considerações que se seguem apoio-me parcialmente, sem envolvê-los em possíveis equívocos meus, em Arantes (2004) e Safatle (2008).
} 
Que relação tem isso, porém, com a via de mão dupla entre a realidade material e as ideias sobre ela que acabamos de apontar? Para responder essa pergunta é preciso considerar que essa falsa consciência esclarecida, ou razão cínica, transforma a ideologia numa questão de repetição de rituais materiais, já que não há mais engano a ser detectado no nível das ideias, pois tudo é posto pela consciência. Ela se desloca então desse plano para o plano das práticas e, pois, para o plano da produção da própria vida social. A forma como os livros-textos mais celebrados ensinam economia, reforça sobremaneira os mecanismos que garantem a reprodução dessa ordem.

Teríamos chegado assim a um mundo compatível com a máxima de Adorno, para quem a ideologia é a própria mercadoria. Contudo, alguém, com razão, poderá argumentar que, se isso fosse completamente verdadeiro, o discurso pós-moderno não teria tido tanto impacto, assim como a posição retoricista de McCloskey não teria feito tanto sucesso justamente entre os críticos do mainstream. Em outras palavras, este alguém estaria alegando que a mercadoria ainda precisa de seus apêndices ideológicos para se impor como absoluta. ${ }^{14} \mathrm{Em}$ ambos os casos, trata-se de hipóteses em investigação na seara da teoria crítica que Marx inaugurou, e a complexidade do capitalismo atual com sua igualmente complexa relação entre o plano material e o plano do ideário parece indicar que pode haver espaço para ambas.

\section{UMA OBSERVAÇÃO FINAL}

Quem me acompanhou até aqui poderá com razão argumentar que a história que contei é uma narrativa que só convence aos já convertidos. Aceito a crítica, mas creio que, a despeito disso, há elementos nela que não podem ser negados, como sugere, por exemplo, a publicação recente (2006), do livro de Eric Beinhocker sugestivamente intitulado $A$ origem da riqueza. De orientação aparentemente hayekiana, e, portanto, muito distante da postura crítica de inspiração marxista que aqui esposei, o livro de Beinhocker apoia-se nos desenvolvimentos recentes da ciência da complexidade para fazer uma crítica demolidora do mainstream e pleitear, nada mais nada menos, que uma radical reconstrução da ciência econômica, partindo do zero, e associando-a não à dedução ou à indução, mas, para o arrepio de muitos, ao modelo funcional, típico da biologia. Não se trata aqui de defender o referido trabalho, mas simplesmente de assinalar quão sintomática é sua publicação enquanto tal e como ela sugere que a indefinição metodológica da ciência econômica está ainda muito distante de ser resolvida.

${ }^{14}$ Para uma defesa dessa posição, veja Eagleton (1998). 


\section{REFERÊNCIAS BIBLIOGRÁFICAS}

ARANTES, Paulo Eduardo (1996). “O paradoxo do intelectual”. In: Ressentimento da Dialética: dialética e experiência intelectual em Hegel. São Paulo, Paz e Terra

(1996a). "Ideia e ideologia”. In: Ressentimento da Dialética: dialética e experiência intelectual em Hegel. São Paulo, Paz e Terra

(2004). "Beijando a cruz". In: Zero à Esquerda. São Paulo, Conrad Livros, coleção Baderna

ARROW, Kenneth (1989). "Workshop on the economy as an evolving complex system: summary". In: P. Anderson et al. (eds), Economy as an Evolving Complex System. New York, Addison-Wesley

BEINHOCKER, Eric D. (2006). The Origin of Wealth - Evolution, Complexity and the Radical Remaking of Economics. Boston, Massachusetts, Harvard Business School Press

BIANCHI, Ana Maria (1998). “Are Brazilian economists differents?” Revista Brasileira de Economia, volume 52, n. 3, julho-setembro

BLACK, Max (1971). “A justificação da Indução”. In: Sidney Morgenbesser (org.). Filosofia da Ciência. São Paulo, Cultrix

BRESSER-PEREIRA, LUIZ CARLOS (2003). “Os dois métodos da teoria econômica”. In: Textos para Discussão - Escola de Economia - FGV/SP, n. 127, julho (2006). The Two Methods of Economics. Disponível em: www.bresserpereira.org.br

CALDWELL, Bruce J. (1984). Beyond Positivism: Economic Methodology in the Twentieth Century. London, George Allen \& Unwin Publishers Ltd.

COASE, Ronald (1937/1990). "The nature of the firm". In: The Firm, the Market and the Law. Chicago, the University of Chicago Press

COMTE, August (1830-1842/1978). Curso de Filosofia Positiva. In: Comte. São Paulo, Abril Cultural, coleção "Os Pensadores"

CHERNAVSKY, Emílio (2007). Sobre a Construção da Política Econômica: uma discussão sobre os determinantes da taxa real de juros no Brasil. IPE/USP, Dissertação de Mestrado

DAVIS, John B. (1998). "David Ricardo”. In: John B. Davis, D. Wade Hands e Uskali Mäki (eds). The Handbook of Economic Methodology. Cheltenham, UK, Edward Elgard Publishing Ltd.

EAGLETON, Terry (1998). As Ilusões do Pós-Modernismo. São Paulo, Jorge Zahar

ELSTER, Jon (1989). “ Marxismo, funcionalismo e Teoria dos Jogos”. Lua Nova, n. 17

EVENSKY, Jerry (1998). “Adam Smith”. In: John B. Davis, D. Wade Hands e Uskali Mäki (eds). The Handbook of Economic Methodology. Cheltenham, UK, Edward Elgard Publishing Ltd.

FEYERABEND, Paul K. (1977). Contra o Método. Rio de Janeiro, Francisco Alves

FOLEY, Duncan, K. (2003). Unholy Trinity - Labor, Capital and Land in the new Economy. London, Routledge

FRIEDMAN, Milton (1953). Essays in Positive Economics. Chicago, The University of Chicago Press.

GEORGESCU-ROEGEN, Nicholas (1971). The Entropy Law and the Economic Process. Cambridge, MA, Harvard University Press.

HAHN, Frank (1984). Equilibrium and Macroeconomics. Oxford, Basil Blackwell

HAYEK, Friedrich A (1937/1948). "Economics and knowledge”. In: Friedrich Hayek, Individualism and Economic Order. Indiana, Gateway

HEGEL, G. W. F (1817/1985). Fenomenologia del Espiritu. Cidade do México, Fondo de Cultura

JANSSEN, Maarteen C. W. (1998). “Aggregation”. In: John B. Davis, D. Wade Hands e Uskali Mäki (eds). The Handbook of Economic Methodology. Cheltenham, UK, Edward Elgard Publishing Ltd.

(1998a). "Microfoundations". In: John B. Davis, D. Wade Hands e Uskali Mäki (eds). The Handbook of Economic Methodology. Cheltenham, UK, Edward Elgard Publishing Ltd.

JARSULIC, Marc (1998). "Chaos in economics”. In: John B. Davis, D. Wade Hands e Uskali Mäki (eds). The Handbook of Economic Methodology. Cheltenham, UK, Edward Elgard Publishing Ltd.

KUHN, Thomas (1962/1975). A Estrutura das Revoluções Científicas. São Paulo, Perspectiva 
MÄKI, Uskali (1998). “Ronald Coase”. In: John B. Davis, D. Wade Hands e Uskali Mäki (eds). The Handbook of Economic Methodology. Cheltenham, UK, Edward Elgard Publishing Ltd.

MANKEW, N. Gregory (2001). Introdução à Economia. São Paulo, Editora Campus

MARX, Karl (1844/1979) - A Ideologia Alemã (Feuerbach). São Paulo, Livraria Editora de Ciências Humanas

(1867/1983). “O Capital - prefácio à 2ª edição”. In: Marx. São Paulo, Abril Cultural, coleção "Os Economistas".

MATTOS, Laura V. (1998). Economia Política e Mudança Social - A Filosofia Econômica de John Stuart Mill. São Paulo, Edusp, FAPRSP.

MCCLOSKEY, D. (1985). The Rethoric of Economics. Madison, The University of Visconsin Press

MILL, John Stuart (1836/1979). "Da definição de economia política e do método de investigação próprio a ela”. In: Bentham/Stuart Mill. São Paulo, Abril Cultural, coleção “Os Pensadores”. (1843/1987). The Logic of Moral Science. London, Open Court

NAGEL, Ernest (1981). La Structura de la Ciência. Barcelona, Paidós

NICOLAIDES, Phedon (1990). "The impossibility of consistent preferences: methodological implications". In: Methodus - Bulletin of the International Network for Economic Method, volume 2, n. 2, dezembro.

PAUlANI, Leda M. (2005). Modernidade e Discurso Econômico. São Paulo, Boitempo

POPPER, Karl (1980). “A lógica da investigação científica”. In: Popper, São Paulo, Abril Cultural, coleção "Os Pensadores".

PRADO, Eleutério (2006). "Uma formalização da mão invisível”. Estudos Econômicos, volume 36, n. 1

RIZVI, S. Abu Turab (1998). "Utility”. In: John B. Davis, D. Wade Hands e Uskali Mäki (eds). The Handbook of Economic Methodology. Cheltenham, UK, Edward Elgard Publishing Ltd.

ROGEBERT, Ole e NORDBERG, Morten (2005). "A defence of absurd theories in economics". The Journal of Economic Methodology, volume 12, n. 4, dezembro.

SAFATLE, Vladimir (2008). "Was ist zynismus". In: Cinismo e Falência da Crítica. São Paulo, Boitempo.

SEN, Amartya (1978). "Rational fools: a critique of the behavioural foundations of economic theory". In: H. Harris (ed). Scientific Models and Man. Oxford, Oxford University Press.

SMITH, Adam (1776/1985). "Uma investigação sobre a natureza e as causas da riqueza das nações. In: Adam Smith. São Paulo, Abril Cultural, coleção “Os Economistas” 